BMJ Open Ophthalmology

\section{Ocular side effects of antirheumatic medications: a qualitative review}

To cite: M Castillejo Becerra C, Ding Y, Kenol B, et al. Ocular side effects of antirheumatic medications: a qualitative review. BMJ Open Ophthalmology 2020;5:e000331. doi:10.1136/ bmjophth-2019-000331

- Additional material is published online only. To view please visit the journal online (http://dx.doi.org/10.1136/ bmjophth-2019-000331).

CMCB and YD contributed equally.

Received 9 May 2019 Revised 29 September 2019 Accepted 9 November 2019
Check for updates

\section{(C) Author(s) (or their} employer(s)) 2020. Re-use permitted under CC BY-NC. No commercial re-use. See rights and permissions. Published by BMJ.

${ }^{1}$ College of Medicine, Ohio State University, Columbus, Ohio, USA ${ }^{2}$ Division of Rheumatology and Immunology, Ohio State University, Columbus, Ohio, USA ${ }^{3}$ Department of Ophthalmology, Ohio State University, Columbus, Ohio, USA

Correspondence to Dr Alexa Simon Meara; Alexa. meara@osumc.edu

\section{ABSTRACT}

Topic This paper reviews the ocular side effects of medications used in the treatment of rheumatological conditions.

Clinical relevance Rheumatic diseases are inflammatory conditions that may affect the skin, blood vessels, joints, muscles and internal organs. Immunosuppressive agents are often used as treatment and while powerful, they carry side effects and toxicities that need careful monitoring. Ophthalmic complications have been reported with the use of antirheumatic medications; however, there is a lack of literature synthesising these reports. This paper addresses this gap and hopes to inform both rheumatologists and ophthalmologists as they work together on the management of patients with rheumatological conditions. Methods PubMed literature search was conducted from November to September 2019 searching for ocular side effects with the use of 25 rheumatological drugs.

Results A total of 111 papers were included in this review. Adverse side effects were divided into non-infectious and infectious causes. Traditional disease-modifying antirheumatic drugs (DMARDs) were associated with pruritus, irritation and dryness of the conjunctiva while biologic DMARDS showed reports of new-onset/recurrent uveitis and demyelinating conditions. Infectious side effects included episodes of cytomegalovirus retinitis, toxoplasmic chorioretinitis and endophthalmitis. Other serious side effects were encountered and included in this review.

Conclusion The goal of this paper is to inform healthcare providers about potential ocular side effects from rheumatological medications. Healthcare providers are encouraged to learn more about these ophthalmic complications and find relevance within their clinical practice.

\section{INTRODUCTION}

Rheumatic diseases are inflammatory conditions that may affect the skin, blood vessels, joints, muscles and internal organs. Standard of care focuses on targeting this overactive inflammatory response with the use of diseasemodifying antirheumatic drugs (DMARDS). For those patients with inadequate response, the newer biologic agents have proven to be effective therapeutic options. While these therapies have revolutionised the treatment of rheumatic diseases, they are not free of toxicity. Many ophthalmic complications have been reported with the use of traditional and biologic DMARDS.

Hydroxychloroquine is one of the most well-known rheumatological drugs used in the treatment of systemic lupus erythematosus. Due to the risk of irreversible retinopathy, the American Academy of Ophthalmology recommends a baseline fundus examination and annual screening after 5 years. ${ }^{1}$ Another commonly used class of drugs are the corticosteroids which are associated with the development of early cataracts and glaucoma. $^{2}$ They also lead to impaired glucose control, which by itself is a major risk factor for diabetic eye disease. In the case of nonselective non-steroidal anti-inflammatory drugs (NSAIDs), ocular manifestations are clinically rare but may include corneal crystal deposition and the development of corneal oedema. $^{3}$ For cyclooxygenase-2 (COX-2) inhibitors, conjunctivitis and blurred vision are two main adverse effects. ${ }^{4}$ Because antirheumatic medications can lead to a wide range of ocular toxicities, it is important for rheumatologists and ophthalmologists to work together in order to recognise these side effects and treat them early. In this paper, we review the ocular side effects of medications used in the treatment of common rheumatological conditions.

\section{METHODS}

\section{Search strategy}

Literature search was performed using PubMed, selecting for case reports, case series, reviews articles, retrospective/prospective studies and clinical trials available as of September 2019. The following search strategy was used for each of the antirheumatic agents: (generic drug name OR trade drug name) AND (adverse effects OR side effects OR adverse) AND (eye diseases OR eye OR ocular OR ophthalmic). A total of 25 antirheumatic agents were included in this review, with their names and class summarised in table 1. In addition, we reviewed the cases reported on the National Registry of 
Table 1

\begin{tabular}{|c|c|c|}
\hline \multicolumn{3}{|l|}{ Antirheumatic medications } \\
\hline Class & Generic name & Trade name \\
\hline \multicolumn{3}{|l|}{ Traditional DMARDs } \\
\hline \multirow[t]{4}{*}{ Antimetabolites } & Azathioprine & Azasan, Imuran \\
\hline & Methotrexate & Rheumatrex, Trexall, Otrexup, Rasuvo \\
\hline & Mycophenolate mofetil & CellCept \\
\hline & Leflunomide & Arava \\
\hline T-cell/calcineurin inhibitor & Ciclosporin & Neoral, Gengraf, Sandimmune \\
\hline Alkylating agent & Cyclophosphamide & \\
\hline Aminosalicylate & Sulfasalazine & Azulfidine, Sulfazine \\
\hline PDE4 inhibitor & Apremilast & Otezla \\
\hline \multirow[t]{2}{*}{ Janus kinase inhibitors } & Baricitinib & Olumiant \\
\hline & Tofacitinib & Xeljanz \\
\hline \multicolumn{3}{|l|}{ Biologic DMARDs } \\
\hline \multirow[t]{4}{*}{ TNF inhibitor-monoclonal antibody } & Infliximab & Remicade \\
\hline & Adalimumab & Humira \\
\hline & Golimumab & Simponi \\
\hline & Certolizumab pegol & Cimzia \\
\hline $\begin{array}{l}\text { TNF inhibitor-soluble TNF receptor } \\
\text { fusion protein }\end{array}$ & Etanercept & Enbrel \\
\hline \multirow[t]{2}{*}{ IL-1 antagonist } & Anakinra & Kineret \\
\hline & Canakinumab & Ilaris \\
\hline \multirow[t]{2}{*}{ IL-6 antagonist } & Sarilumab & Kevzara \\
\hline & Tocilizumab & Actemra \\
\hline IL-12, IL-23 inhibitor & Ustekinumab & Stelara \\
\hline \multirow[t]{2}{*}{ IL-17 inhibitor } & Secukinumab & Consentyx \\
\hline & Ixekizumab & Taltz \\
\hline \multirow[t]{2}{*}{ Antilymphocytic agents } & Rituximab & Rituxan \\
\hline & Abatacept & Orencia \\
\hline
\end{tabular}

Interferons

Interferon type 1

Interferon alpha

DMARD, disease-modifying antirheumatic drug; TNF, tumour necrosis factor.

Ocular Side effects and those recommended by outside reviewers. Duplicates were removed from the study.

\section{Study selection}

Titles and abstracts were screened for relevance and full-text manuscripts were obtained. If electronic copies were unavailable, efforts were made to request full-length manuscripts through the Health Sciences Library at The Ohio State University. From search results, articles that involve the antirheumatic medication of interest and discussion regarding ocular side effects in humans were identified. Studies were excluded from this review for several reasons: (1) unavailability of full-length articles; (2) multiple-drug treatments confounding effect of an individual drug; (3) unclear or vague ocular side effects; (4) lack of convincing evidence for cause and effect. The process of identification, screening, selection and exclusion criteria used in this review are summarised in figure 1 .

\section{Assessment of methodological quality}

The quality for each case report and case series was assessed using the tool proposed by Murad et al, ${ }^{5}$ limited to questions 2-6. The following questions suggest whether the methodological quality is low or high based on a binary response (yes or no): (1) Was the exposure adequately ascertained? (2) Was the outcome adequately ascertained? (3) Were other alternative causes that may explain the observation ruled out? (4) Was there a challenge/rechallenge phenomenon? (5) Was there a dose-response effect? The quality assessment scores and characteristics for each study are summarised in online supplementary table S1. 


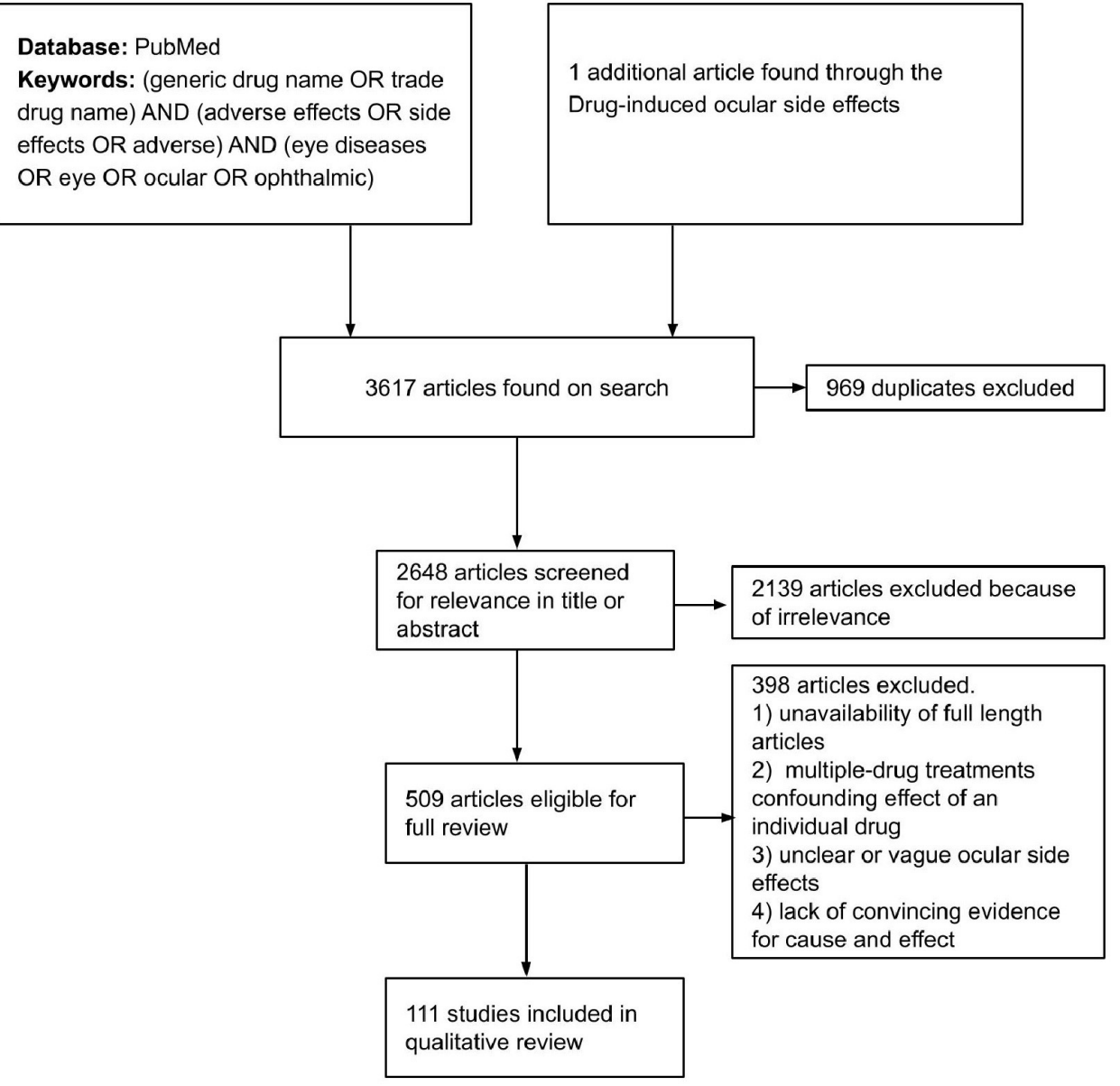

Figure 1 Flow diagram of study selection process.

\section{Data synthesis}

A total of 111 studies were included in this paper with a summary of the non-infectious and infectious side effects for each antirheumatic agents reported on table 2. No attempts were made for statistical analysis. We excluded hydroxychloroquine, corticosteroids and NSAIDs from the current review as their ocular side effects are well established in the literature.

\section{RESULTS}

\section{Traditional DMARDs}

DMARDs are commonly used as part of the initial medications for rheumatic diseases. Some of the medications in this group include azathioprine, methotrexate, mycophenolate mofetil, leflunomide, ciclosporin and cyclophosphamide.

\section{Azathioprine}

Azathioprine is the S-imidazolyl derivative of 6-mercaptopurine. It is an analogue of purine, which acts purine metabolism and nucleic acid synthesis to inhibit. Azathioprine is used in both antineoplastic and immunosuppressive processes due to its cytotoxic effects, known reduction of antibody production, decrease in B-cell production and decrease in T-cell-mediated responses. ${ }^{6}$ Like other immunosuppressants, azathioprine can lower immune response and there have been reports of cytomegalovirus (CMV) retinitis and toxoplasmosis reactivation associated with the treatment of inflammatory bowel disease. $^{78}$

\section{Methotrexate}

Methotrexate competitively inhibits dihydrofolate reductase, disrupting the synthesis of purine and thymidylic acid. The result is reduced cellular proliferation, especially on highly proliferative cells and tissues. In a group of 13 patients receiving intermittent high-dose methotrexate $(30-250 \mathrm{mg} / \mathrm{kg})$, there were reported symptoms of generalised pruritus, burning, irritation and blurred vision. ${ }^{9}$ Generalised eye symptoms such as conjunctivitis, dry eyes and blepharitis were also noted in patients who received methotrexate as part of their chemotherapy regimen for postmolar gestational trophoblastic neoplasia. ${ }^{10}$ There is also a case report of internuclear ophthalmoplegia in a 26-year-old man after receiving intrathecal methotrexate for lymphoma. ${ }^{11}$ Four case reports in 1992, 2002, 2005 and 2006 described optic disc swelling and visual field defects suspected to be optic neuropathy from methotrexate use. ${ }^{12-15}$ There is one case report of intraocular lymphoma after 9 months of treatment for temporal arteritis with prednisone and methotrexate ${ }^{16}$ and another case of presumed methotrexate-induced mucosa-associated lymphoid tissue (MALT) lymphoma in 78-year-old female patient 
Table 2

\section{Ocular side effects of antirheumatic medications}

\begin{tabular}{llll}
\hline Drug & Non-infectious side effects & Infectious side effects & References \\
\hline Azathioprine & $\begin{array}{l}\text { Retardation in corneal wound healing in albino } \\
\text { rabbits }\end{array}$ & $\begin{array}{l}\text { CMV retinitis, ocular toxoplasmosis } \\
\text { reactivation }\end{array}$ & 6-8 \\
Methotrexate & $\begin{array}{l}\text { Pruritus, burning, irritation, blurred vision, } \\
\text { coniunctivitis, dry eyes, blepharitis, internuclear }\end{array}$ & None reported & 9-21
\end{tabular}

conjunctivitis, dry eyes, blepharitis, internucle defects, intraocular lymphoma, retinal cotton wool spots, corneal epitheliopathy

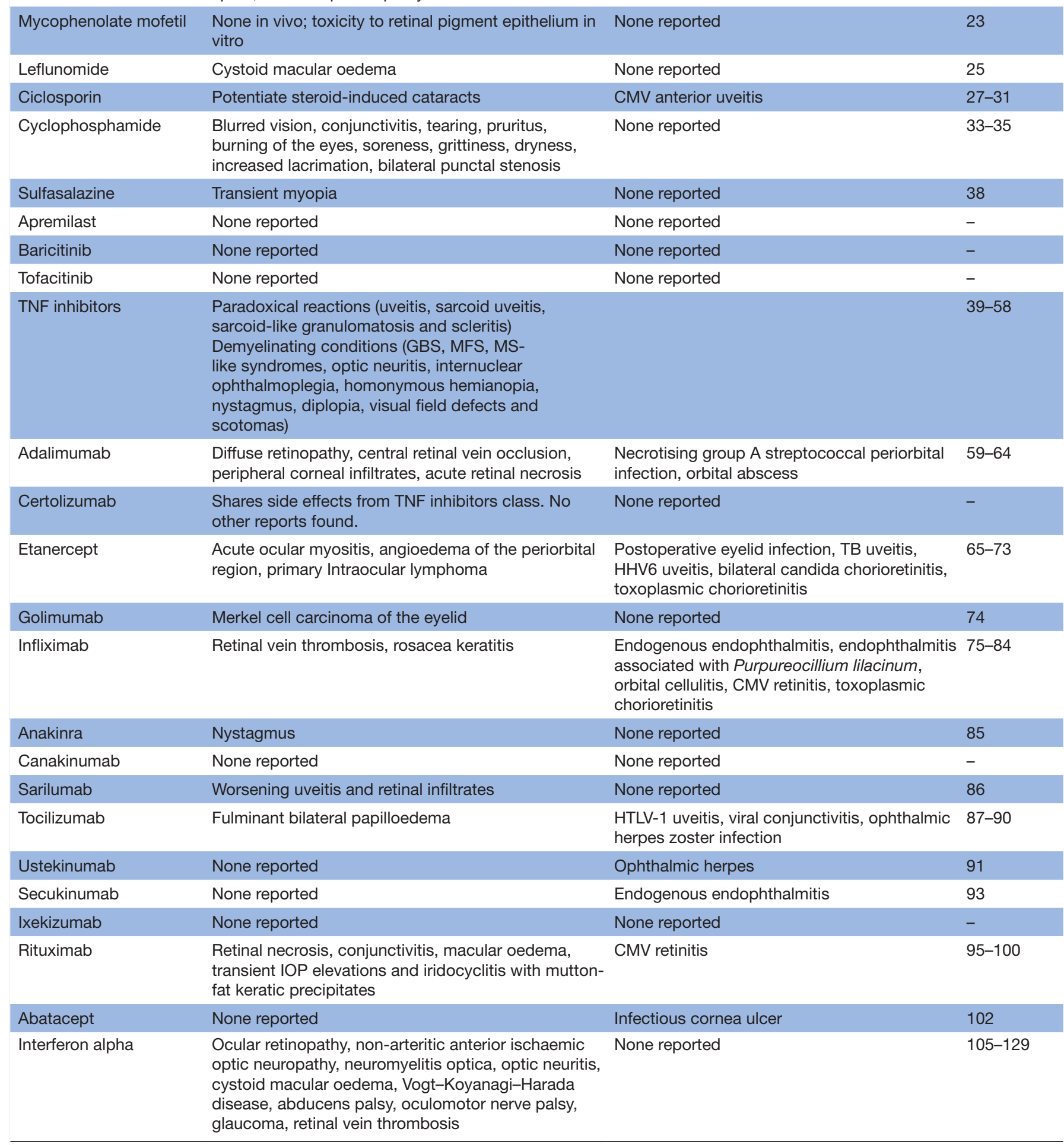

CMV, cytomegalovirus; GBS, Guillian-barre Syndrome ; HHV6, human herpesvirus 6; HTLV-1, human T-cell leukaemia-lymphoma virus 1; IOP, intraocular pressure; MFS, Miller Fisher Syndrome; MS, Multiple Sclerosis; TB, tuberculosis; TNF, tumour necrosis factor. 
with rheumatoid arthritis treated with methotrexate for $>8$ years.${ }^{17}$ However, a large observational study following 19591 patients over 89710 person-years found no significant increased risk of lymphoma with methotrexate among patients with rheumatoid arthritis. ${ }^{18}$ There are case reports of retinal cotton wool spots after either intravitreal or systemic methotrexate. ${ }^{19}{ }^{20}$ Case reports of corneal epitheliopathy were also noted after intravitreal injection of methotrexate for intraocular lymphoma. ${ }^{21}$

\section{Mycophenolate mofetil}

Mycophenolate mofetil inhibits inosine monophosphate dehydrogenase, preventing synthesis of purine nucleotides and reducing the production of lymphocytes. ${ }^{22}$ Originally used in the management of transplant patients, it is now used for the treatment of various autoimmune conditions such as uveitis. Search over PubMed did not yield reports of ocular side effects. Of interest, in vitro experiments showed decrease cell viability in human retinal pigment epithelium. ${ }^{23}$

\section{Leflunomide}

Once absorbed in the body, leflunomide is converted to teriflunomide. It can then inhibit the enzyme dihydroorotate dehydrogenase and block the synthesis of ribonucleotide uridine monophosphate pyrimidine required for the synthesis of DNA and RNA. ${ }^{24}$ A case report from 2004 shows a patient treated with leflunomide who developed bilateral cystoid macular oedema after 2 weeks of initiation of the drug. According to the report, the macular oedema symptoms resolved after cessation of leflunomide. ${ }^{25}$

\section{Ciclosporin}

Ciclosporin is an inhibitor of T-cell-mediated responses. ${ }^{26}$ It is a binder of cytoplasmic proteins called cyclophilins, with the subsequent complex that inhibits calcineurin. This process decreases activation of cytokines. There is a report of CMV anterior uveitis after topical ciclosporin A $0.05 \%$ ophthalmic emulsion. ${ }^{27}$ Interestingly, the patient was not being infected with HIV and had been on ciclosporin eye emulsion for dry eyes. A study of 51 subjects was conducted comparing ocular side effects of different combinations of immunosuppressive regimen after renal transplant: steroids plus ciclosporin, steroids plus azathioprine, or steroids plus azathioprine plus ciclosporin. There was no statistically significant difference in macular hyperpigmentation or cataracts among these groups. ${ }^{28}$ However, another study in 2003 of 140 subjects suggested that ciclosporin may potentiate steroid-induced cataracts. In this study, subjects were divided into two groups: one group received azathioprine plus steroids, another group received azathioprine plus steroids and ciclosporin. Despite the decrease in total dose of steroids with the addition of ciclosporin, more subjects in the ciclosporin group showed higher level of steroid-induced cataracts. ${ }^{29}$

Ciclosporin A treatment in Behcet's disease was also shown to be associated with more central nervous system
(CNS) manifestations including internuclear ophthalmoplegia and diplopia. In a retrospective chart review of 117 patients with Behcet's disease, 6 of 21 patients were identified with new onset of neurological disease while being treated with ciclosporin A for maintenance therapy, while none of the patients on other medications showed new CNS manifestations. With ciclosporin level above therapeutic range, there are reports of ciclosporin-associated encephalopathies. In all six patients, ciclosporin A level was within therapeutic range. ${ }^{30}$ A case report from 2001 also mentioned diplopia and eye abduction weakness bilaterally in a patient who received ciclosporin after allogeneic bone marrow transplantation. MRI demonstrated white-matter abnormalities. The symptoms ceased 2 days after stopping ciclosporin. ${ }^{31}$

\section{Cyclophosphamide}

Cyclophosphamide is an immunosuppressive agent known for its high potency and use in organ-threatening autoimmune manifestations such as vasculitis and lupus nephritis. It is an alkylating agent that interferes with DNA replication, thus inducing cellular apoptosis. Cyclophosphamide activation takes place in the liver, and it can be administered either parenterally or orally. ${ }^{32}$ On review, there are reports of blurred vision with its use on patients with cancer, lasting from less than an hour to 14 days. ${ }^{33}$ The combination of cyclophosphamide, methotrexate and 5-fluorouracil (CMF) was commonly used in breast cancer treatment. In these patients, CMF therapy has been associated with conjunctivitis with symptoms such as tearing and pruritus in up to $42 \%$ of patients. ${ }^{34}$ In another study regarding ocular symptoms associated with CMF therapy from 2001, patients experienced soreness, grittiness, dryness and increased lacrimation. One patient developed bilateral punctal stenosis after second round of CMF. ${ }^{35}$

\section{Sulfasalazine}

In the colon, bacteria break down sulfasalazine into sulfapyridine and 5-aminosalicylic acid. Its mechanism of action has not been fully elucidated, but several theories, such as inhibition of nuclear factor-kappa B or tumour necrosis factor-alpha (TNF- $\alpha$ ), are proposed. ${ }^{36} 37$ We found one case of transient myopia in 2003 following the addition of sulfasalazine for the treatment of rheumatoid arthritis. Following initiation of sulfasalazine $2 \mathrm{~g}$ daily for 3 weeks, visual acuity decreased from -3.0 to -4.0 DS to -1.0 DS. The medication was subsequently stopped with improved myopia and stable vision on examination. ${ }^{38}$

\section{Other small-molecule DMARDs}

Newer immunosuppressive medications were also reviewed. Apremilast (brand name Otezla) is a phosphodiesterase- 4 inhibitor used in treatment of psoriatic arthritis. Baricitinib (brand name Olumiant) and tofacitinib (Xeljanz) are Janus kinase (Jak) enzyme inhibitors. As of this article's publication, these drugs did not have reports of ocular toxicity. 


\section{Biologic DMARDs}

Biologic drugs are the newer class of antirheumatic medications. Unlike traditional DMARDS, these target specific components of the immune response. Current agents include the TNF inhibitors (adalimumab, certolizumab, etanercept, golimumab and infliximab), anakinra, canakinumab, sarilumab, tocilizumab, ustekinumab, secukinumab, ixekizumab, rituximab and abatacept.

\section{TNF inhibitors}

TNF- $\alpha$ is a cytokine critical for the initiation and propagation of the immune response. TNF inhibitors block this important molecule and are used in the treatment of rheumatoid arthritis, psoriatic arthritis, juvenile arthritis, inflammatory bowel disease, ankylosing spondylitis and psoriasis. Although effective, caution is warranted as they make patients more susceptible to infection, malignancy and a wide range of systemic side effects. In the case of ocular side effects, uveitis is among the most commonly reported adverse events. This is known as the paradoxical reaction of anti-TNF agents, where we find the appearance or exacerbation of a condition that can normally be treated with this therapy. ${ }^{39}$ TNF inhibitors have shown to be effective at reducing the frequency of uveitis flares in patients with Behcet disease, juvenile idiopathic arthritis (JIA), spondyloarthropathies, inflammatory bowel disease and sarcoidosis. ${ }^{40}$ On the other hand, a number of case reports associate new-onset uveitis with the initiation of anti-TNF therapy, with etanercept as the main culprit. In terms of molecular structure, etanercept is a soluble TNF receptor fusion protein, while others such as infliximab, adalimumab, golimumab and certolizumab are known to be monoclonal antibodies. To shine light at these effects, Wendling et al conducted a populationbased cohort study and identified 31 cases of new-onset uveitis in patients treated with TNF inhibitors for ankylosing spondylitis (19 cases), psoriatic arthritis (4 cases), rheumatoid arthritis (6 cases) and juvenile idiopathic arthritis (2 cases) ${ }^{41}$ Most of these occurred with the use of etanercept (23/31 cases). The authors also conducted a literature analysis and identified 121 additional cases of new-onset uveitis; etanercept was found to be implicated on $84.3 \%$ of these cases. Other paradoxical reactions of TNF inhibitors include sarcoid uveitis, sarcoid-like granulomatosis and scleritis. ${ }^{42-48}$

This class of antirheumatic medications has also been attributed to the development of central and peripheral demyelination diseases such as GuillainBarre, Miller-Fisher and other syndromes resembling multiple sclerosis. ${ }^{495}$ Ratnarajan et al describe a case of a 43-year-old woman who started infliximab therapy 9 weeks prior and presented with 3 days of worsening diplopia. ${ }^{51}$ On presentation, she was found to have mild ophthalmoparesis, pupillary unresponsiveness, lid twitches, lid hops and very high anti-GQ1b antibody titres. Intravenous immunoglobulin and plasmapheresis were avoided. Instead, her diplopia was managed with occlusion, with all symptoms resolving within 10 weeks.
Optic neuritis is another demyelinating disorder that is widely attributed to TNF inhibitors. ${ }^{52}$ In 2013, the results of the SABER study were released. ${ }^{53}$ This was a large multi-institutional research initiative which showed optic neuritis to be rare among those who initiated anti-TNF therapy, approximately 5-10 per 100000 patient-years, and occurring with similar frequency among those receiving non-biologic DMARD therapy. These findings opposed the large number of optic neuritis cases found in the literature and are important to consider as one makes conclusions about the adverse effects of TNF inhibitors. Other neurological side effects of TNF inhibition include internuclear ophthalmoplegia, homonymous hemianopia, nystagmus, diplopia, visual field defects and scotomas. ${ }^{54-58}$ We will now focus on the ocular adverse effects of the individual TNF inhibitors.

\section{Adalimumab}

A case of diffuse bilateral retinopathy was found in a woman treated with adalimumab for Crohn's disease. ${ }^{59}$ Treatment was discontinued, but visual field loss persisted 6 months later. Hsu et alreport a case of central retinal vein occlusion after the fifth dose of adalimumab for refractory psoriasis. ${ }^{60}$ Although adalimumab was discontinued, the patient developed neovascular glaucoma resulting in vision loss. Another patient treated for Crohn's disease with a bimonthly dose of adalimumab developed bilateral peripheral corneal infiltrates 36 hours after injection. ${ }^{61}$ These were treated with topical corticosteroids but recurred after each treatment over the following weeks. Schechet $e t$ al describe a case of acute retinal necrosis in a patient treated for psoriasis. ${ }^{62} \mathrm{He}$ underwent intravenous acyclovir and prophylactic laser barricade therapy; 7 years later, he was 20/20 without history of retinal detachment.

In terms of infectious side effects, a woman developed severe necrotising periorbital infection while receiving treatment with adalimumab. ${ }^{63}$ She made a complete recovery after antibiotic therapy. There is also a report of an 11-year-old girl treated for chronic recurrent multifocal osteomyelitis with adalimumab who then developed acute sinusitis complicated by an orbital abscess and subdural empyema. ${ }^{64}$ She underwent rhinosurgery and neurosurgery with intravenous antibiotics and had no long-term neurological sequelae.

\section{Etanercept}

Two separate case reports describe the use of etanercept and the development of orbital myositis. ${ }^{6566}$ In one case, the patient developed ocular myositis a few months after initiation therapy, while in the other case, the patient developed symptoms a decade later. Both were treated with discontinuation of etanercept and high-dose steroid therapy. Another adverse effect of etanercept is the development of periorbital angioedema seen in the treatment of adult-onset Still's disease. ${ }^{67}$ There is also a risk of primary intraocular lymphoma due to the immunosuppressive effects of etanercept as reported in a 50-year-old woman who was successfully treated with 
serial intravitreal methotrexate injections and systemic chemotherapy. ${ }^{68}$ For eyelid surgery, we found a case of postoperative eyelid infection in a patient taking etanercept. ${ }^{69}$ Additional cases of tuberculosis, human herpesvirus 6 , bilateral candida and toxoplasmic uveitis were identified which speak to the immunodeficient state in patients receiving etanercept therapy. ${ }^{70-73}$

\section{Golimumab}

We found a case of eyelid Merkel cell carcinoma in a patient treated with golimumab for chronic rheumatoid arthritis. ${ }^{74}$ The patient developed the tumour 6 months after initiation therapy and was treated with radical tumour excision, eyelid reconstruction, and radiation therapy of the eyelid and lymph nodes.

\section{Infliximab}

Multiple reports mentioned the development of retinal vein thrombosis with infliximab treatment in the setting of Crohn's disease, ulcerative colitis, plaque psoriasis and rheumatoid arthritis. ${ }^{75-78}$ Based on the temporal effects of infliximab therapy and thrombosis, the authors advocated for a causal relationship. Fasci-Spurio and Thompson described a case of severe bilateral rosacea-like keratopathy in a patient receiving infliximab therapy for rheumatoid arthritis. ${ }^{79}$ The patient had a long-standing history of acne rosacea of the skin with ocular symptoms that began with infliximab therapy and improved with its withdrawal. Infectious side effects such as CMV retinitis, toxoplasmic chorioretinitis, orbital cellulitis and endogenous endophthalmitis have also been attributed to infliximab. ${ }^{73} 80-83$ In particular, Purpureocillium lilacinum endophthalmitis was diagnosed in a 71-year-old patient receiving infliximab for surgically induced necrotising scleritis. He was successfully treated with 27 -gauge vitrectomy, and after 2 months of antibacterial and antifungal therapy, there was visual recovery. ${ }^{84}$

\section{Anakinra and canakinumab}

The interleukin-1 receptor antagonist anakinra can be used for rheumatoid arthritis and neonatal-onset multisystem inflammatory disease (NOMID). A cohort study examined the 5-year outcomes of 26 patients with NOMID treated with anakinra $1-5 \mathrm{mg} / \mathrm{kg} /$ day for at least 36 months. ${ }^{85}$ While visual acuity and peripheral vision remained stable, two patients on high-dose treatment developed nystagmus. Other manifestations included eye swelling, glaucoma and blurred vision with low-dose anakinra, and blepharospasm, eye pruritus and blurred vision with the high dose. Canakinumab targets interleukin-1 beta. Literature review did not yield case reports for the ocular side effects of canakinumab.

\section{Sarilumab}

Sarilumab works against the interleukin-6 receptor and can be used for moderate to severe rheumatoid arthritis. The phase II SATURN study investigated its efficacy and safety for the treatment of posterior segment non-infectious uveitis. ${ }^{86}$ Subcutaneous administration reduced vitreous haze on these patients with the most common adverse events being worsening uveitis and retinal infiltrates.

\section{Tocilizumab}

Tocilizumab is another interleukin-6 receptor inhibitor; it treats rheumatoid arthritis, giant cell arteritis and juvenile idiopathic arthritis. In a report by Roux et al, a patient developed ophthalmic herpes zoster virus infection with duplex bilateralis following 9 months of tocilizumab treatment. ${ }^{87}$ Her infection combined the right ophthalmic region with vesicles on the tip, side and root of the nose, and the left C4 metamere with lesions on the anterior part of the shoulder. Symptoms improved with valacyclovir treatment and relapse again after each tocilizumab injection despite dose reduction. Tocilizumab was ultimately stopped. Another report by Terada et al showed recurrence of human T-cell leukaemia-lymphoma virus 1 (HTLV-1) uveitis and HTLV-1-associated myelopathy/ tropical spastic paraparesis with tocilizumab administration. HTLV-1 symptoms improved with steroid-based therapy but worsened again with abatacept substitution. ${ }^{88}$ The authors called for caution with the use of biologics in HTLV-1-infected individuals. A multicentre study on the use of tocilizumab for JIA-associated uveitis found one case of viral conjunctivitis and bullous impetigo that required temporary discontinuation of therapy. ${ }^{89}$ Therapy was later restarted with no new adverse events. Burstzyn et al showed bilateral papilloedema in a child with steroid-dependent systemic JIA and tocilizumab treatment. ${ }^{90}$ After urgent unilateral optic nerve sheath fenestration, vision was completely restored in one eye and partially recovered in the contralateral eye.

\section{Ustekinumab}

Ustekinumab blocks interleukin 12 and 23 to help patients with plaque psoriasis, psoriatic arthritis and severe Crohn's disease. Under the safety information for Stelera (ustekinumab), an episode of ophthalmic herpes was reported. ${ }^{91}$ No other adverse events were found on the literature.

\section{Secukinumab}

Secukinumab is a monoclonal antibody that binds to the protein interleukin 17A and is used to treat psoriatic arthritis, plaque arthritis and ankylosing spondylitis. ${ }^{92} \mathrm{In}$ a report by Martinez et al, a diabetic patient developed osteomyelitis and unilateral endogenous endophthalmitis following secukinumab therapy. ${ }^{93}$ Interleukin 17 inhibitor therapy was viewed as a predisposing factor for infection. On the other hand, no reports associate ixekizumab with ocular side effects.

\section{Rituximab}

Rituximab causes antibody-mediated B-cell depletion. It can be useful in rheumatoid arthritis, certain forms of vasculitis and haematological cancers. ${ }^{94}$ In terms of side effects, a case of acute retinal necrosis was reported in a patient with scleroderma and rheumatoid arthritis 
treated with rituximab. ${ }^{95} \mathrm{~A}$ patient with microscopic polyangiitis also developed progressive outer retinal necrosis following rituximab and cyclophosphamide therapy. ${ }^{96}$ Another reported side effect of rituximab is transient bilateral conjunctivitis, which was seen during infusion therapy for bronchial associated lymphoma. ${ }^{97}$ Cystoid macular oedema was also reported in two patients with refractory granulomatosis with polyangiitis receiving rituximab. $^{98}$ In terms of infectious side effects, Chan et alfound CMV retinitis to be more frequent in patients receiving concomitant rituximab and fludarabine-containing regimens than patients receiving fludarabine-containing regimens alone. Treatment in these patients require both intravitreal and systemic ganciclovir/foscarnet therapy progressing to secondary retinal atrophy in all patients and leading to blindness in $86 \%$ of affected eyes. ${ }^{99}$ While most reported side effects have been the result of systemic treatment, intravitreal rituximab injections can lead to transient intraocular pressure (IOP) elevations and iridocyclitis with mutton-fat keratic precipitates as seen in the treatment of primary vitreoretinal lymphoma. ${ }^{100}$

\section{Abatacept}

Abatacept works by binding to CD80/CD86 proteins on antigen-presenting cells and preventing T-cell activation. It is often prescribed after failure of first-line therapy in patients with moderate to severe rheumatoid arthritis. ${ }^{101}$ One study looked at its efficacy and safety profile in Sjogren's syndrome secondary to rheumatoid arthritis. ${ }^{102}$ Here, abatacept was associated with an infectious cornea ulcer that resolved with antibiotic eye drops.

\section{Interferon alpha}

Interferons are proteins released in response to viruses. Pegylated interferon has been used for treatment of hepatitis C infection. More recently, interferon alpha had been recommended for consideration in patients with Behcet's disease, especially those with sight-threatening or refractory uveitis. ${ }^{103} 104$ However, it is also known that interferon alpha can cause retinopathy, with possible optic nerve damage in severe cases. ${ }^{105}$

Case reports of episcleritis are associated with interferon alpha-2b in the treatment of head and neck mucosal melanoma. ${ }^{106}$ There are also reports of non-arteritic anterior ischaemic optic neuropathy, neuromyelitis optica, optic neuritis, retinopathy, cystoid macular oedema, Vogt-Koyanagi-Harada disease, abducens palsy, oculomotor nerve palsy, glaucoma and retinal vein thrombosis reported in patients treated with interferon alpha. ${ }^{107-129}$

\section{DISCUSSION}

While the surge of new antirheumatic agents has significantly improved patient outcomes, their widespread use raises safety concerns. ${ }^{130} 131$ All aforementioned drugs have immunosuppressive properties and carry the theoretical risk of ocular infections. At the same time, many of these drugs have non-infectious ocular side effects that are shared or unique among the class of medications.
Dosage is an important consideration which has not been fully elucidated due to the heterogeneity among different studies and lack of dose comparison within a given study. As an example of dose-related side effects, we have the cohort study of 26 patients with NOMID treated with low-dose $(\leq 2.5 \mathrm{mg} / \mathrm{kg} /$ day $)$ or high-dose anakinra $(>2.5 \mathrm{mg} / \mathrm{kg} /$ day $) .{ }^{85}$ While two patients in the high-dose group developed nystagmus compared with zero patients in the low-dose group, the small number of patients and affected individuals prevents generalised statements about dosage. Another consideration is the route of administration which was difficult to analyse as most of the rheumatological agents included in this review used only one route. It does appear that intravitreal and topical applications have more corneal specific side effects when compared with their systemic counterparts, as was seen with intravitreal methotrexate in cases of corneal epitheliopathy ${ }^{21}$ and intravitreal rituximab with mutton-fat keratic precipitates. ${ }^{100}$

As conclusions are made based on this study, one must be aware of the following limitations. First, the literature search was conducted using PubMed, which can miss cases and studies not included in this search engine. Second, as a qualitative review, no conclusions can be made regarding the frequency or incidence of reported side effects. Third, most of the ocular toxicities came from case reports, which are considered the lowest level of evidence and lack direct proof of cause and effect. To address the last concern, efforts were made to evaluate the quality of each case report and case series using the framework proposed by Murad et al. ${ }^{5}$ Based on a set of five questions, most of the studies received a score of 3 or less which we deemed as low evidence. Only a handful of studies received a score of 4 or more because they included a challenge/rechallenge phenomenon or dose-response effect.

In summary, this study adds to the well-known ocular side effects of medications such as steroids, NSAIDS and hydroxychloroquine. It also calls for close collaboration between rheumatologists and ophthalmologists so that they can remain vigilant of medication-induced ocular side effects. Through early recognition and intervention, healthcare providers can address potentially serious and devastating effects to their patient's vision while reaping the benefits of anti-rheumatic medications.

Acknowledgements The authors thank The Health Sciences Library at The Ohio State University for technical assistance.

Contributors All authors contributed to the idea, writing and editing of the manuscript.

Funding The authors have not declared a specific grant for this research from any funding agency in the public, commercial or not-for-profit sectors.

Competing interests None declared.

Patient consent for publication Not required.

Provenance and peer review Not commissioned; externally peer reviewed.

Open access This is an open access article distributed in accordance with the Creative Commons Attribution Non Commercial (CC BY-NC 4.0) license, which permits others to distribute, remix, adapt, build upon this work non-commercially, 
and license their derivative works on different terms, provided the original work is properly cited, appropriate credit is given, any changes made indicated, and the use is non-commercial. See: http://creativecommons.org/licenses/by-nc/4.0/.

ORCID iD

Alexa Simon Meara http://orcid.org/0000-0002-8406-3556

\section{REFERENCES}

1 Marmor MF, Kellner U, Lai TYY, et al. Recommendations on screening for chloroquine and hydroxychloroquine retinopathy (2016 revision). Ophthalmology 2016;123:1386-94.

2 Renfro L, Snow JS. Ocular effects of topical and systemic steroids. Dermatol Clin 1992;10:505-12.

3 Hoppmann RA, Peden JG, Ober SK. Central nervous system side effects of nonsteroidal anti-inflammatory drugs. Aseptic meningitis, psychosis, and cognitive dysfunction. Arch Intern Med 1991:151:1309-13.

4 Fraunfelder FW, Solomon J, Mehelas TJ. Ocular adverse effects associated with cyclooxygenase-2 inhibitors. Arch Ophthal 2006;124:277-9.

5 Murad MH, Sultan S, Haffar S, et al. Methodological quality and synthesis of case series and case reports. BMJ Evidence-Based Medicine 2018;23:60-3.

6 Ahmed AR, Moy R, Azathioprine MR. Azathioprine. Int J Dermatol 1981;20:461-7.

7 Ammari W, Berriche O. Rétinite cytomégalovirus chez un patient atteint de rectocolite hémorragique sous azathioprine [CMV retinitis in a patient with ulcerative colitis taking azathioprine]. Pan Afr Med $J$ 2015;21:227.

8 Puga M, Carpio D, Sampil M, et al. Ocular toxoplasmosis reactivation in a patient with inflammatory bowel disease under treatment with azathioprine. J Clin Gastroenterol 2016;50:610.

9 Doroshow JH, Locker GY, Gaasterland DE, et al. Ocular irritation from high-dose methotrexate therapy: pharmacokinetics of drug in the tear film. Cancer 1981:48:2158-62.

10 Maestá I, Nitecki R, Horowitz NS, et al. Effectiveness and toxicity of first-line methotrexate chemotherapy in low-risk postmolar gestational trophoblastic neoplasia: The New England Trophoblastic Disease Center experience. Gynecol Oncol 2018;148:161-7.

11 Lepore FE, Nissenblatt MJ. Bilateral internuclear ophthalmoplegia after intrathecal chemotherapy and cranial irradiation. Am J Ophthalmol 1981:92:851-3.

12 Johansson BA. Visual field defects during low-dose methotrexate therapy. Doc Ophthalmol 1992;79:91-4.

13 Sbeity ZH, Baydoun L, Schmidt S, et al. Visual field changes in methotrexate therapy. Case report and review of the literature. $J$ Med Liban 2006;54:164-7.

14 Balachandran C, McCluskey PJ, Champion GD, et al. Methotrexate-Induced optic neuropathy. Clin Exp Ophthalmol 2002;30:440-1.

15 Clare G, Colley S, Kennett R, et al. Reversible optic neuropathy associated with low-dose methotrexate therapy. J Neuroophthalmol 2005;25:109-12.

16 Rizkalla K, Rodrigues S, Proulx A, et al. Primary intraocular lymphoma arising during methotrexate treatment of temporal arteritis. Can J Ophthalmol 2005:40:585-92.

17 Kobayashi Y, Kimura K, Fujitsu Y, et al. Methotrexate-associated orbital lymphoproliferative disorder in a patient with rheumatoid arthritis: a case report. Jpn J Ophthalmol 2016:60:212-8.

18 Kempen JH, Gangaputra S, Daniel E, et al. Long-term risk of malignancy among patients treated with immunosuppressive agents for ocular inflammation: a critical assessment of the evidence. Am J Ophthalmol 2008;146:802-12.

19 Kuroiwa N, Abematsu N, Matsuo Y, et al. [A case of intraocular lymphoma having retinal adverse events associated with intravitreal methotrexate]. Nippon Ganka Gakkai Zasshi 2011;115:611-6.

20 Klemencic S. Cotton wool spots as an indicator of methotrexateinduced blood dyscrasia. Optometry 2010;81:177-80.

21 Gorovoy I, Prechanond T, Abia M, et al. Toxic corneal epitheliopathy after intravitreal methotrexate and its treatment with oral folic acid. Cornea 2013;32:1171-3.

22 Allison AC, Eugui EM. Mycophenolate mofetil and its mechanisms of action. Immunopharmacology 2000;47:85-118.

23 Zacharias LC, Damico FM, Kenney MC, et al. In vitro evidence for mycophenolic acid dose-related cytotoxicity in human retinal cells. Retina 2013;33:2155-61.

24 Breedveld FC, Dayer JM. Leflunomide: mode of action in the treatment of rheumatoid arthritis. Ann Rheum Dis 2000;59:841-9.
25 Barak A, Morse LS, Leflunomide SI. Arava-induced cystoid macular oedema. Rheumatology 2004;43:246-8.

26 Kahan BD. Cyclosporine. N Engl J Med 1989;321:1725-38.

27 Siak J, Chee S-P. Cytomegalovirus anterior uveitis following topical cyclosporine A. Ocul Immunol Inflamm 2018;26:90-3.

28 Apaydin C, Gur B, Yakupoglu G, et al. Ocular and visual side effects of systemic cyclosporine. Ann Ophthalmol 1992;24:465-9.

29 Nakamura Tet al. Influence of cyclosporin on steroid-induced cataracts after renal transplantation. Jpn J Ophthalmol 2003;47:254-9.

30 Kötter I, Günaydin I, Batra M, et al. CNS involvement occurs more frequently in patients with Behcet's disease under cyclosporin $A$ (CsA) than under other medications - results of a retrospective analysis of 117 cases'. Clin Rheumatol 2006;25:482-6.

31 Openshaw $\mathrm{H}$. Eye movement abnormality associated with cyclosporin. J Neurol Neurosurg Psychiatry 2001;70:809.

32 de Jonge ME, Huitema ADR, Rodenhuis S, et al. Clinical pharmacokinetics of cyclophosphamide. Clin Pharmacokinet 2005;44:1135-64

33 Kende G, Sirkin SR, Thomas PRM, et al. Blurring of vision. A previously undescribed complication of cyclophosphamide therapy. Cancer 1979;44:69-71.

34 Loprinzi CL, Love RR, Garrity JA, et al. Cyclophosphamide, methotrexate, and 5-fluorouracil (CMF)-induced ocular toxicity. Cancer Invest 1990;8:459-65.

35 Stevens A, Spooner D. Lacrimal duct stenosis and other ocular toxicity associated with adjuvant cyclophosphamide, methotrexate and 5 -fluorouracil combination chemotherapy for early stage breast cancer. Clin Oncol 2001;13:438-40.

36 Lee C-K, Lee EY, Chung SM, et al. Effects of disease-modifying antirheumatic drugs and antiinflammatory cytokines on human osteoclastogenesis through interaction with receptor activator of nuclear factor kappaB, osteoprotegerin, and receptor activator of nuclear factor kappaB ligand. Arthritis Rheum 2004;50:3831-43.

37 Rodenburg RJ, Ganga A, van Lent PL, et al. The antiinflammatory drug sulfasalazine inhibits tumor necrosis factor alpha expression in macrophages by inducing apoptosis. Arthritis Rheum 2000;43:1941-50

38 Santodomingo-Rubido J, Gilmartin B, Wolffsohn JS. Drug-induced bilateral transient myopia with the sulphonamide sulphasalazine. Oph Phys Optics 2003;23:567-70.

39 Toussirot Éric, Aubin F. Paradoxical reactions under TNF- $\alpha$ blocking agents and other biological agents given for chronic immunemediated diseases: an analytical and comprehensive overview. RMD Open 2016;2:e000239.

40 Cordero-Coma M, Sobrin L. Anti-tumor necrosis factor- $\alpha$ therapy in uveitis. Surv Ophthalmol 2015;60:575-89.

41 Wendling D, Paccou J, Berthelot J-M, et al. New onset of uveitis during anti-tumor necrosis factor treatment for rheumatic diseases. Semin Arthritis Rheum 2011;41:503-10.

42 Hashkes PJ, Shajrawi I. Sarcoid-related uveitis occurring during etanercept therapy. Clin Exp Rheumatol 2003;21:645-6.

43 Suzuki J, Goto H. Uveitis associated with sarcoidosis exacerbated by etanercept therapy. Jpn J Ophthalmol 2009:53:439-40.

44 Dragnev D, Barr D, Kulshrestha M, et al. Sarcoid panuveitis associated with etanercept treatment, resolving with adalimumab. Case Reports 2013;2013:bcr2013200552.

45 Seve P, Varron L, Broussolle C, et al. Sarcoid-related uveitis occurring during adalimumab therapy. Ocul Immunol Inflamm 2012;20:59-60.

46 Clementine RR, Lyman J, Zakem J, et al. Tumor necrosis factor-alpha antagonist-induced sarcoidosis. J Clin Rheumatol 2010;16:274-9.

47 Wladis EJ, Tarasen AJ, Roth ZJ, et al. Orbital sarcoid-like granulomatosis after inhibition of tumor necrosis factor- $\alpha$. Ophthal Plast Reconstr Surg 2016;32:e30-2.

48 Gaujoux-Viala C, Giampietro C, Gaujoux T, et al. Scleritis: a paradoxical effect of etanercept? Etanercept-associated inflammatory eye disease. J Rheumatol 2012;39:233-9.

49 Shin I-SJ, Baer AN, Kwon HJ, et al. Guillain-Barré and Miller Fisher syndromes occurring with tumor necrosis factor $\alpha$ antagonist therapy. Arthritis Rheum 2006;54:1429-34.

50 Theibich A, Dreyer L, Magyari M, et al. Demyelinizing neurological disease after treatment with tumor necrosis factor alpha-inhibiting agents in a rheumatological outpatient clinic: description of six cases. Clin Rheumatol 2014;33:719-23.

51 Ratnarajan G, Thompson A, Dodridge C, et al. Novel variant of Miller Fisher syndrome occurring with tumor necrosis factor $\alpha$ antagonist therapy. JAMA Neurol 2015;72:1377-8.

52 Simsek I, Erdem H, Pay S, et al. Optic neuritis occurring with antitumour necrosis factor therapy. Ann Rheum Dis 2007;66:1255-8. 
53 Winthrop KL, Chen L, Fraunfelder FW, et al. Initiation of antiTNF therapy and the risk of optic neuritis: from the safety assessment of biologic thERapy (SABER) study. Am J Ophthalmol 2013:155:183-9.

54 Clifford LJ, Rossiter JD. Peripheral visual field loss following treatment with etanercept. Br J Ophthalmol 2004;88:842.

55 Rossman MD, Newman LS, Baughman RP, et al. A double-blinded, randomized, placebo-controlled trial of infliximab in subjects with active pulmonary sarcoidosis. Sarcoidosis Vasc Diffuse Lung Dis 2006;23:201-8.

56 HH D, Mohamed A, Klistorner A, et al. Ophthalmic manifestations of demyelination secondary to etanercept. Clin Exp Ophthalmol 2008;36:392-4.

57 Papadia M, Herbort CP. Infliximab-induced demyelination causes visual disturbance mistaken for recurrence of HLA-B27-related uveitis. Ocul Immunol Inflamm 2010;18:482-4.

58 Drury J, Hickman SJ. Internuclear ophthalmoplegia associated with anti-TNF $\alpha$ medication. Strabismus 2015;23:30-2.

59 Marticorena-Álvarez P, Chaparro M, Pérez-Casas A, et al. Probable diffuse retinopathy caused by adalimumab in a patient with Crohn's disease. J Crohns Colitis 2012;6:950-3.

60 Hsu C-K, Cheng C-Y, Hung J-H, et al. Central retinal vein occlusion and subsequent neovascular glaucoma after adalimumab treatment for psoriasis. Clin Exp Dermatol 2014;39:72-3.

61 Matet A, Daruich A, Beydoun T, et al. Systemic adalimumab induces peripheral corneal infiltrates: a case report. BMC Ophthalmol 2015;15:57.

62 Schechet SA, Garff K, Klima K, et al. Acute retinal necrosis after administration of adalimumab, a systemic antitumor necrosis factor antibody. Retin Cases Brief Rep 2018;12:307-9.

63 Roos JCP, René C, Ostor AJK. Necrotizing group A streptococcal periorbital infection following adalimumab therapy for rheumatoid arthritis. Cutan Ocul Toxicol 2011;30:160-2.

64 Kofoed MS, Fisker N, Christensen AE, et al. Sinogenic intracranial complications: is adalimumab a culprit? Case Reports 2018;2018:bcr-2017-221449.

65 Caramaschi P, Biasi D, Carletto A, et al. Orbital myositis in a rheumatoid arthritis patient during etanercept treatment. Clin Exp Rheumatol 2003;21:136-7.

66 Couderc M, Mathieu S, Tournadre A, et al. Acute ocular myositis occurring under etanercept for rheumatoid arthritis. Joint Bone Spine 2014;81:445-6.

67 Kato T, Noguchi K, Uehara M, et al. Angioedema of the periorbital region that developed during treatment with etanercept in a case of refractory adult-onset Still's disease. Intern Med 2012;51:2801-4.

68 Song WK, Cho AR, Yoon YH. Highly suspected primary intraocular lymphoma in a patient with rheumatoid arthritis treated with etanercept: a case report. BMC Ophthalmol 2018;18:156.

69 Yakopson VS, Flanagan JC. Postoperative eyelid infection in a patient taking etanercept. Orbit 2011;30:303-4.

70 Fonollosa A, Artaraz J, Les I, et al. Sarcoid intermediate uveitis following etanercept treatment: a case report and review of the literature. Ocul Immunol Inflamm 2012;20:44-8.

71 Glâtre F, Rousseau E, Bacin F. Uvéite unilatérale avec polymerase chain reaction positive pour HHV6 dans l'humeur aqueuse chez une patiente sous étanercept : propos d'un cas [Unilateral uveitis with HHV6-positive polymerase chain reaction in aqueous humor for an etanercept-treated woman: a case report]. J Fr Ophtalmol 2010;33:561-3.

72 Arriola-Villalobos P, Díaz-Valle D, Alejandre-Alba N, et al. Bilateral Candida chorioretinitis following etanercept treatment for hidradenitis suppurativa. Eye 2008;22:599-600.

73 Lassoued S, Zabraniecki L, Marin F, et al. Toxoplasmic chorioretinitis and antitumor necrosis factor treatment in rheumatoid arthritis. Semin Arthritis Rheum 2007;36:262-3.

74 Hanafi H, Verdijk RM, Paridaens D. Eyelid Merkel cell carcinoma in a patient treated with golimumab. Orbit 2018;37:21-5.

75 Puli SR, Benage DD. Retinal vein thrombosis after infliximab (remicade) treatment for Crohn's disease. Am J Gastroenterol 2003;98:939-40.

76 Veerappan SG, Kennedy M, O'Morain CA, et al. Retinal vein thrombosis following infliximab treatment for severe left-sided ulcerative colitis. Eur J Gastroenterol Hepatol 2008;20:588-9.

77 Vergou T, Moustou AE, Maniateas A, et al. Central retinal vein occlusion following infliximab treatment for plaque-type psoriasis. Int J Dermatol 2010;49:1215-7.

78 Diniz B, Barbosa CP, Regatieri CV, et al. Oclusão de ramo venoso da retina associado ao uso de infliximabe: relato de caso [Branch retinal vein occlusion following infliximab treatment: case report]. Arq Bras Oftalmol 2011;74:214-6.
79 Fasci-Spurio F, Thompson A. Cytomegalovirus retinitis in a patient treated with anti-tumor necrosis factor alpha antibody therapy for rheumatoid arthritis. Clin Infect Dis 2004;39:e88-94.

80 Madill S, Koay P, Mansfield D, et al. Sight-threatening keratopathy complicating anti-TNF therapy in Crohn's disease: a case report. Inflamm Bowel Dis 2014;20:E2-3.

81 Haerter G, Manfras BJ, de Jong-Hesse Y, et al. Cytomegalovirus retinitis in a patient treated with anti-tumor necrosis factor alpha antibody therapy for rheumatoid arthritis. Clin Infect Dis 2004;39:e88-94.

82 Roos JCP, Ostor AJK. Orbital cellulitis in a patient receiving infliximab for ankylosing spondylitis. Am J Ophthalmol 2006;141:767-9.

83 Agarwal P, Gallaghar M, Murphy E, et al. Endogenous endophthalmitis in a rheumatoid patient on tumor necrosis factor alpha blocker. Indian J Ophthalmol 2007;55:230-2.

84 Yoshida M, Yokokura S, Kunikata H, et al. Endophthalmitis associated with Purpureocillium lilacinum during infliximab treatment for surgically induced necrotizing scleritis, successfully treated with 27-gauge vitrectomy. Int Ophthalmol 2018;38:841-7.

85 Sibley CH, Plass N, Snow J, et al. Sustained response and prevention of damage progression in patients with neonatalonset multisystem inflammatory disease treated with anakinra: a cohort study to determine three- and five-year outcomes. Arthritis Rheumatism 2012;64:2375-86.

86 Heissigerová J, Callanan D, de Smet MD, et al. Efficacy and safety of sarilumab for the treatment of posterior segment noninfectious uveitis (SARIL-NIU): the phase 2 SATURN study. Ophthalmology 2018:pii: S0161-6420(18)30474-3.

87 Roux C, Breuil V, Albert C, et al. Ophthalmic herpes zoster infection in patients with rheumatoid arthritis who were treated with tocilizumab. J Rheumatol 2011;38:399.

88 Terada Y, Kamoi K, Ohno-Matsui K, et al. Treatment of rheumatoid arthritis with biologics may exacerbate HTLV-1-associated conditions. Medicine 2017;96:e6021.

89 Calvo-Río V, Santos-Gómez M, Calvo I, et al. Anti-Interleukin-6 receptor tocilizumab for severe juvenile idiopathic arthritisassociated uveitis refractory to anti-tumor necrosis factor therapy: a multicenter study of twenty-five patients. Arthritis Rheumatol 2017;69:668-75.

90 Burstzyn L, Levin S, Rotenberg B, et al. Fulminant bilateral papilloedema during low-dose steroid taper in a child with systemic idiopathic arthritis treated with tocilizumab. Clin Exp Rheumatol 2017;35:149-51.

91 Stelara. Ustekinumab [package insert]. Bloomington, IN: Janssen Biotech, Inc, 2016.

92 Lønnberg AS, Zachariae C, Skov L. Targeting of interleukin-17 in the treatment of psoriasis. Clin Cosmet Investig Dermatol 2014;7:251-9.

93 Martinez CE, Allen JB, Davidorf FH, et al. Endogenous endophthalmitis and osteomyelitis associated with interleukin 17 inhibitor treatment for psoriasis in a patient with diabetes. BMJ Case Rep 2017;56:pii: bcr-2017-219296.

94 Weiner GJ. Rituximab: mechanism of action. Semin Hematol 2010:47:115-23.

95 Schuler S, Brunner M, Bernauer W. Rituximab and acute retinal necrosis in a patient with scleromalacia and rheumatoid arthritis. Ocul Immunol Inflamm 2016;24:96-8.

96 Dogra M, Bajgai P, Kumar A, et al. Progressive outer retinal necrosis after rituximab and cyclophosphamide therapy. Indian $J$ Ophthalmol 2018;66:591-3.

97 Marinella MA. Bilateral conjunctivitis due to rituximab. Ann Pharmacother 2007;41:1318.

98 Bussone G, Kaswin G, de Menthon M, et al. Macular oedema following rituximab infusion in two patients with Wegener's granulomatosis. Clin Exp Rheumatol 2010;28:90-2.

99 Chan TSY, Cheung CYM, Yeung IYL, et al. Cytomegalovirus retinitis complicating combination therapy with rituximab and fludarabine. Ann Hematol 2015;94:1043-7.10.1007/s00277-0142296-5

100 Hashida N, Ohguro N, Nishida K. Efficacy and complications of intravitreal rituximab injection for treating primary vitreoretinal lymphoma. Trans/ Vis Sci Technol 2012;1:1.

101 Ruderman EM, Pope RM. Drug insight: abatacept for the treatment of rheumatoid arthritis. Nat Clin Pract Rheumatol 2006;2:654-60.

102 Tsuboi H, Matsumoto I, Hagiwara S, et al. Efficacy and safety of abatacept for patients with Sjögren's syndrome associated with rheumatoid arthritis: rheumatoid arthritis with orencia trial toward Sjögren's syndrome Endocrinopathy (ROSE) trial-an open-label, one-year, prospective study-interim analysis of 32 patients for 24 weeks. Modern Rheumatology 2015;25:187-93. 
103 Hatemi G, Christensen R, Bang D, et al. Update of the EULAR recommendations for the management of Behçet's syndrome. Ann Rheum Dis 2018;2018:808-18.

104 Sullu Y. The results of interferon-alpha treatment in Behçet uveitis. Ocul Immunol Inflamm 2019;4:1-7.

105 Rentiya ZS, Wells M, Bae J, et al. Interferon- $\alpha$-induced retinopathy in chronic hepatitis $C$ treatment: summary, considerations, and recommendations. Graefes Arch Clin Exp Ophthalmol 2019;257:447-52.

106 Yang L, Ji S, Wang L, et al. Episcleritis in a patient with mucosal melanoma treated with interferon alfa- $2 \mathrm{~b}$ and radiotherapy: a case report. J Med Case Rep 2018;12:388.

107 Iferkhass S, Elasri F, Chatioui S, et al. [Bilateral non-arteritic ischemic optic neuropathy during treatment of viral hepatitis $C$ with pegylated interferon and ribavirin]. J Fr Ophtalmol 2015;38:34-40.

108 Mangioni D, Soria A, Brighina L, et al. A case of classic neuromyelitis optica (Devic's syndrome) triggered by pegylatedinterferon $\alpha$. BMC Pharmacol Toxicol 2014;15:56.

109 Sahidt Ortega-Ibarra F, Remes-Troche JM. Retinal thrombosis secondary to the combination therapy of pegylated interferon and ribavirin for chronic hepatitis $\mathrm{C}$ virus infection: a rare complication. Rev. esp. enferm. dig. 2013;105:291-2.

110 Kawazoe T, Araki M, Lin Y, et al. New-Onset type 1 diabetes mellitus and anti-aquaporin-4 antibody positive optic neuritis associated with type 1 interferon therapy for chronic hepatitis $C$. Intern Med 2012;51:2625-9.

111 Kang HY, Shin MC. Pegylated interferon-associated severe retinopathy in a patient with chronic hepatitis. Korean J Ophthalmol 2012;26:147-50.

112 Monzon JG, Hammad N, Stevens SD, et al. Retinopathy associated with adjuvant high-dose interferon-2b in a patient with resected melanoma: a case report and review of the literature. Oncologist 2012;17:384-7.

113 Knyazer B, Lifshitz T, Marcus M, et al. Anterior ischemic optic neuropathy in a patient with hepatitis $C$ treated with interferonalpha and ribavirin. Isr Med Assoc J 2011;13:251-3.

114 Sheth H, Michaelides M, Siriwardena D. Cystoid macular edema and visual loss as sequelae to interferon alpha treatment of systemic hepatitis C. Indian J Ophthalmol 2010;58:147-8.

$115 \mathrm{Lim}$ JH, Lee YN, Kim YS, et al. Vogt-Koyanagi-Harada disease occurring during PEGylated interferon- $\alpha 2 b$ and ribavirin combination therapy for chronic hepatitis C. Korean J Hepatol 2011;17:61-5.

116 Narkewicz MR, Rosenthal P, Schwarz KB, et al. Ophthalmologic complications in children with chronic hepatitis $\mathrm{C}$ treated with pegylated interferon. J Pediatr Gastroenterol Nutr 2010;51:183-6.
117 Fragoso YD, Paggiaro MSS, Mastromauro R, et al. Literature systematic review on the ophthalmological side effects of interferons. Arq Bras Oftalmol 2011;74:306-10.

118 Novelli FJde, Przysiezny A, Rosa EL, et al. Ophthalmologic findings in hepatitis $C$ patients treated with pegylated interferon $\alpha-2 b$ and ribavirin. Arq Bras Oftalmol 2014;77:178-81.

119 Panetta JD, Gilani N. Interferon-Induced retinopathy and its risk in patients with diabetes and hypertension undergoing treatment for chronic hepatitis $\mathrm{C}$ virus infection. Aliment Pharmacol Ther 2009;30:597-602

120 Rodney AJ, Gombos DS, Pagliaro LC, et al. Ischemic optic neuropathy associated with low-dose interferon alfa: report of two cases. Am J Clin Oncol 2009;32:86-7.

121 Sène $\mathrm{D}$, Touitou $\mathrm{V}$, Bodaghi $\mathrm{B}$, et al. Intraocular complications of IFN- $\alpha$ and ribavirin therapy in patients with chronic viral hepatitis $\mathrm{C}$. WJG 2007;13:3137-40.

122 Oishi A, Miyamoto K, Kashii S, et al. Abducens palsy and Sjogren's syndrome induced by pegylated interferon therapy. $\mathrm{Br} \mathrm{J}$ Ophthalmol 2007;91:843-4.

123 Zandieh I, Adenwalla M, Cheong-Lee C, et al. Retinal vein thrombosis associated with pegylated-interferon and ribavirin combination therapy for chronic hepatitis C. WJG 2006;12:4908-10.

124 Gonçalves LL, Farias AQ, Gonçalves PL. Branch retinal vein thrombosis and visual loss probably associated with pegylated interferon therapy of chronic hepatitis C. WJG 2006;12:4602-3.

125 Nakamura A, Tojo K, Takasu K, et al. Unilateral oculomotor nerve palsy induced by combination therapy of interferon- $\alpha 2 b$ and ribavirin. Intern Med 2005;44:682-3.

126 Ayaki M. Development of neovascular glaucoma in the course of interferon alfa therapy for hepatitis type $\mathrm{C}$. Br J Ophthalmol 1994;78:238.

127 Fukumoto Y, Shigemitsu T, Kajii N, et al. Abducent nerve paralysis during interferon alpha-2a therapy in a case of chronic active hepatitis C. Intern. Med. 1994;33:637-40.

128 Kwon YS, Choe YH, Chin HS. Development of glaucoma in the course of interferon alpha therapy for chronic hepatitis B. Yonsei Med J 2001;42:134-6.

129 KL T, Bowyer J, Schofield K, et al. Severe interferon associated retinopathy. Br J Ophthalmol 2003;87:247-8.

130 Peponis V, Kyttaris VC, Chalkiadakis SE, et al. Review: ocular side effects of anti-rheumatic medications: what a rheumatologist should know. Lupus 2010;19:675-82.

131 Rubbert-Roth A. Assessing the safety of biologic agents in patients with rheumatoid arthritis. Rheumatology 2012;51:v38-47. 